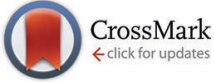

Cite this: Phys. Chem. Chem. Phys., 2016, 18, 24812

Received 22nd July 2016, Accepted 17th August 2016

DOI: $10.1039 / c 6 c p 05101 d$

www.rsc.org/pccp

\section{Nanoparticle electrochemistry}

\author{
Peter H. Robbs and Neil V. Rees* \\ This perspective article provides a survey of recent advances in nanoscale electrochemistry, with a brief \\ theoretical background and a detailed discussion of experimental results of nanoparticle based \\ electrodes, including the rapidly expanding field of "impact electrochemistry". Following this, recent \\ advances in experimental study of exotic nanoparticle electrodes are reviewed.
}

\section{Introduction}

The plethora of physical ${ }^{1,2}$ chemical $^{3-6}$ and catalytic ${ }^{7-10}$ properties of nanoparticles have driven extensive research into nanomaterials. In the realms of electrochemistry the nanoscale has been subject to much interest in both fundamental ${ }^{11}$ and applied ${ }^{12-15}$ science. The benefits of decreasing scale in electrochemistry can, simplistically, be attributed to enhanced mass transport and greatly reduced capacitive charging. The improved signal: noise ratio allows for greater sensitivity towards trace species analysis and better resolution of competitive signals in electroanalysis. ${ }^{16,17}$

This perspective review will focus primarily on advances in novel theoretical and experimental electrochemistry at nanoparticle electrodes, since $2014 .{ }^{18}$ Some of the underlying theory of electrochemistry at nanoparticles will be briefly summarised as a reminder for the reader.

\section{Theoretical aspects of nanoelectrochemistry}

As the critical dimension of an electrode decreases to the (sub)micron scale, the classical theories of electrochemistry can still adequately explain the observed phenomena. However, as the electrode radius shrinks to below $\sim 10 \mathrm{~nm}$, the Butler-Volmer and (continuum) Marcus-Hush formalisms can fall short of a complete description. The detailed theory of electrochemistry at this scale has been reviewed extensively ${ }^{11,19,20}$ but merits an overview.

The effective thickness of the diffusion layer $\left(\delta_{\text {eff }}\right)$ at the nanoelectrode|electrolyte interface can be estimated by:

$$
\delta_{\text {eff }}=r_{0} / A
$$

School of Chemical Engineering, University of Birmingham, Edgbaston, Birmingham, B15 2TT, UK. E-mail: n.rees@bham.ac.uk where $r_{0}$ denotes the nominal electrode radius and $A$ is either, 1 , or $4 / \pi$ for spherical and planar electrodes respectively. ${ }^{21}$ At larger electrodes, where $r_{0} \geq 10^{-7} \mathrm{~m}$, the diffusion layer is considered completely separate from the electrical double layer (EDL). The extent of the diffuse part of the EDL can be estimated, by the Debye length eqn (2), to range from $c a .0 .1-10 \mathrm{~nm}^{22}$ depending on the supporting electrolyte concentration $\left(C_{0}\right)$ :

$$
\kappa^{-1}=\left(\frac{R T \varepsilon \varepsilon_{0}}{\sum_{i} \varrho_{i} e^{2} z_{l}^{2}}\right)^{-\frac{1}{2}}
$$

where $R, T$ and $F$ have their usual meanings, $\varepsilon$ and $\varepsilon_{0}$ are the dielectric constant and vacuum permittivity respectively, $e$ is the elementary charge and $\varrho_{i}$ is the number density of ionic species $i$, of charge $z_{i}$. Relative to the diffuse layer, the EDL is confined to the surface of larger electrodes, and hence can be treated as separate to the diffusion layer. This assumption allows for easier treatment of mass transport to the electrode, using Fick's equations. At nanoelectrodes, however, once $r_{0}$ reaches a comparable scale to $\delta_{\text {eff }}$, the EDL cannot be reasonably treated as separate to the diffuse layer ${ }^{23-25}$ as the layers overlap significantly (Fig. 1).

This overlap can cause non-classical phenomena to complicate analysis at planar nanodisk electrodes, primarily for $r_{0} \leq 5 \mathrm{~nm}^{11}$ The overlap of EDL and diffusion layer can violate the electroneutrality assumption, altering the mass transfer to the smaller nanoelectrodes. Chen et al. ${ }^{26}$ have described that conventional mass transport theories have been found to apply to nanoelectrodes to some extent. It was shown that the limiting current $\left(I_{\text {lim }}\right)$ varied linearly with the concentration of $\left[\mathrm{Fe}\left(\mathrm{CN}_{6}\right)\right]^{3-}$ for all electrode radii considered, however $I_{\lim }$ was shown to be depressed at electrodes where $r_{0}<10 \mathrm{~nm}$. For $r_{0}=5 \mathrm{~nm}, I_{\lim }$ was $\sim 20 \%$ lower than at larger electrodes $\left(r_{0}=9.7 \mu \mathrm{m}\right.$ and $\left.16 \mathrm{~nm}\right) .{ }^{26}$ In this context, near wall hindered diffusion of analyte molecules was not considered. 


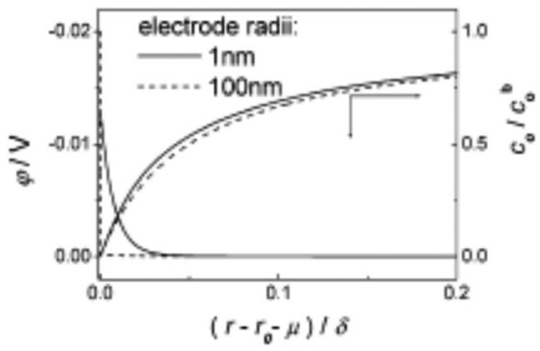

Fig. 1 Theoretical model of the diffusion layer and EDL in the interfacial region of 1 and $100 \mathrm{~nm}$ radii electrodes. Parameters of model reduction reaction were: concentration of analyte and supporting electrolyte were $5 \mathrm{mM}$ and $0.5 \mathrm{M}$ respectively, analyte charge $=-1, k^{0}=1.0 \mathrm{~cm} \mathrm{~s}^{-1}, D=1 \times 10^{-5} \mathrm{~cm} \mathrm{~s}^{-2}, \alpha=\beta=$ 0.5 and $E^{0^{\prime}}=0$. Full details of the computational work is available in ref. 23 . Reproduced with permission of the American Chemical Society.

Finally, the electrode size has an effect on electron transfer (ET) kinetics. At nanoelectrodes much faster ET kinetics can be probed, but the classic Butler-Volmer (BV) approach is not wholly appropriate. The BV formalism is more accurate at smaller overpotentials $(\eta)$, where $\eta$ is close to $E_{\mathrm{f}}^{0}$, which has found general application to study at macro and microelectrodes. This derives from the underlying linearization of the free energy curves of reactants and products, which is most applicable close to $E_{\mathrm{f}}^{0}$ (i.e. small $\eta$ ). In addition, the BV model only considers ET to/from a narrow range of electronic states near the Fermi level of the electrode from/to the electroactive species. These two factors render the BV approach less accurate for ET at nanoelectrodes, where the enhanced mass transport can shift the ET to significantly higher $\eta{ }^{11}$

The quantum Marcus-Hush (MH) and Marcus-Hush-Chidsey (MHC) formalisms can predict more reliable $k_{0}$ values at the larger $\eta$ of nanoelectrodes. The MHC theory in particular, considers the probability of the ET involving the density of states in the electrode (suitably weighted via Fermi-Dirac statistics) for inclusion into the Marcus Theory. Both $\mathrm{MH}$ and MHC formalisms predict similar rate constants, for large reorganisation energies $(\lambda)$, at potential below the inversion predicted by classical $\mathrm{MH}$ theory. Complete discussion of the applicability of the different kinetic analyses can be found in the reviews by Chen and $\mathrm{Liu}^{11}$ and Zhang et al. ${ }^{19,20}$ Feldberg has derived relations to quantify the conditions where $\mathrm{BV}$ and $\mathrm{MHC}$ results diverge or agree, based on $\gamma$ and $\lambda$ (where $\gamma=k_{0} r_{0} / D$ ). ${ }^{27}$ Where the inequality (3) is true, the results are indistinguishable

$$
\log _{10} \gamma>2-\frac{\lambda}{20 k_{\mathrm{B}} T}
$$

whereas the BV and MHC results diverge significantly if relation (4) holds.

$$
\log _{10} \gamma<1-\frac{\lambda}{10 k_{\mathrm{B}} T}
$$

\section{Nanoparticle arrays}

Single disk nanoelectrodes can be challenging to reproduce by a variety of different methods. ${ }^{28}$ Modern micro and nanofabrication technologies are readily capable of fabricating nanoelectrode arrays
(NEAs), ${ }^{29-31}$ however, the procedures are complex and can be very time consuming. A simple alternative approach is to use nanoparticles as a nanoparticle modified electrode. ${ }^{32}$ These can be manufactured by facile nanoparticle casting or electrodeposition methods to create irregular arrays. Arrays can provide an insight into electrochemistry at nanoparticles, at a fundamental level, ${ }^{32,33}$ as well as significant practical applicative use in ions in sensing. ${ }^{12}$

The ideal nanoparticle modified working surface can be approximated as an array of spherical nanoelectrodes on an extended plane. ${ }^{13,32}$ The diffusion layer of each particle in a NEA can be estimated using conventional theories. It follows that the diffusion layer extends into the bulk over time and can interact and overlap, between particles depending on surface coverage, or spacing. ${ }^{13,34}$ As such, the interfacial structure at the NEA dictates the voltammetric response, which can be qualitatively divided into 4 ideal response categories (Fig. 2).

Mass transport in category 1 is convergent, as with (sub)micro electrodes, while at category 4 planar diffusion contributes increasingly to the voltammetric response. As the planar contribution increases, the voltammogram changes from a steady state response to a peak; ${ }^{35}$ micro to macro-type response. There is a fifth conceptual case of the diffusion domain approximation, where a stochastic dispersion of nanoparticles could group into case 3 or 4 type regions, separated by case 1 or dead zones. This fifth case can make detailed analysis challenging because of the need for deconvolution of the different ensemble responses.

Electrodes modified with irregular NEAs have found extensive application in sensors, for detection of analytes including heavy metals, ${ }^{36-40}$ pollutants ${ }^{41}$ and biomolecules and pharmaceuticals. ${ }^{42-46}$ Nanoparticles have been applied to electroanalysis in this way, because of the high degree of selectivity toward analytes, such that trace species like As(III) and $\mathrm{Hg}$ (II) have been determined in
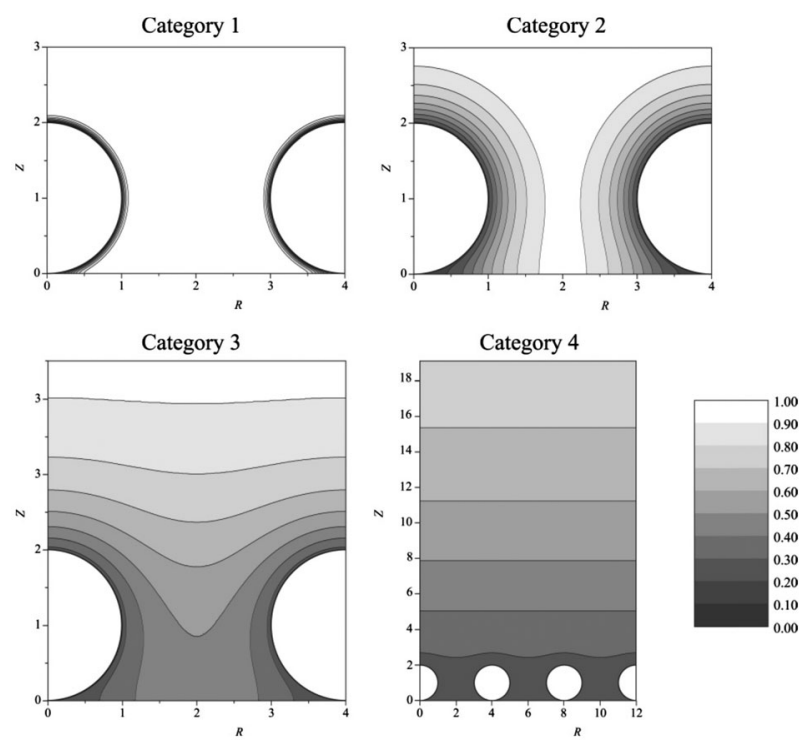

Fig. 2 Simulated concentration profiles at nanoparticle electrode arrays at different dimensionless scan rates $(\sigma)$. Category 1: $\sigma=1000$. Category 2: $\sigma=10$. Category 3: $\sigma=1$. Category 4: $\sigma=0.01$. For all categories, spherical diffusion domain boundary radius $=2$. Reproduced from ref. 13 , with permission of the American Chemical Society. 
the presence of interfering species like $\mathrm{Cu}(\mathrm{II}),{ }^{47}$ The lowest limit of detection (LOD) known to the authors for As(III) was $0.0096 \mathrm{ppb}$ at an AuNP modified glassy carbon electrode, reported by Compton et al. in $2004 .{ }^{48}$ Other commonly studied heavy metals include $\mathrm{Pb}$ (II) (LOD: $0.008 \mathrm{ppb}$ at dimercaptosuccinic acid capped $\mathrm{Fe}_{3} \mathrm{O}_{4} \mathrm{NP}$ modified carbon paste electrode) ${ }^{49}$ and $\mathrm{Cd}(\mathrm{II})$ (LOD: $0.7 \mathrm{ppb}$ at a single walled carbon nanotube film electrode). ${ }^{50}$

Common biomolecules studied include dopamine (DA), Ascorbic acid (AA) and uric adic (UA), all of which can cause interference with one another if analysed collectively. ${ }^{51,52}$ Using anodized titanium sheet electrodes modified with decorated $\mathrm{TiO}_{2}$ nanotubes, Cai et al. ${ }^{51}$ detected DA and UA in the presence of AA in several matrices of different acidities $(\mathrm{pH} 7,5,3)$ with a LOD of $c a .30 \mathrm{nM}$ DA.

\section{Nanoparticle impacts}

While the nanoparticle modified electrodes discussed above are valuable tools, particularly for electroanalysis, it can be computationally demanding to deconvolute signals arising from inhomogeneity in the array structure. The electrochemical study of single nanoparticles, first studied by Heyrovsky et al. ${ }^{53-56}$ in 1995 and developed by Bard et al. in $2007^{57}$ has gained increasing attention as a means of probing the electrochemistry at single nanoparticles. ${ }^{18,58}$ The underlying theory has been established, based on simplifying the nanoparticle-electrode impact to a spherical nanoelectrode in contact with an infinite plane. $I_{\text {lim }}$ can be approximated using classical electrochemical theory for a sphere on an extended plane, ${ }^{57,59}$ where the critical time is on the order of microseconds; the limiting current is reached in $t \approx r_{\mathrm{NP}}^{2} / D_{\mathrm{O}}$. The transient current response during an impact event can be analysed according to the Shoup-Szabo equation. ${ }^{60-66}$ The rapid attainment of $I_{\text {lim }}$ means the peak current of a transient can be recorded at a series of different applied potentials to model a voltammetric response of a single nanoparticle ${ }^{64,67-69}$ of radius $r_{\mathrm{NP}}$. Depending on the experimental conditions, the impinging particle can contact and catalyse a reaction, or be directly subject to a redox process; indirect and direct particle voltammetry respectively. A more detailed discussion of the analytical approaches and value of both general modes is available elsewhere. ${ }^{18}$

\section{Computational results}

The contact between the particle and electrode has been found to be more complicated than a simple electrical contact.

The interface at the substrate electrode, as the active particle approaches, is quantized (Fig. 3), with probabilities associated to the particle passing into the different regions close to the surface. ${ }^{70,71}$ One of the implications of the quantized interface is the occurrence of electron tunnelling when the particle approaches to within the tunnelling region. ${ }^{71}$ Once in the tunnelling region of the substrate, nanoparticles have been shown to be subject to a common colloidal phenomenon $;^{72,73}$ near-wall hindered diffusion. ${ }^{65,70}$ As a particle approaches close to an infinite plane (the substrate electrode), diffusion in the $z$ direction, away from the wall is limited, resulting in an

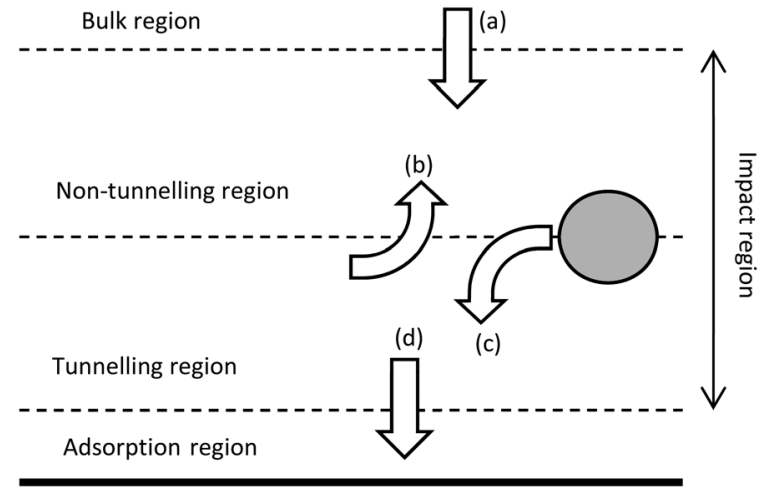

Fig. 3 Schematic of the different regions at the electrode surface (solid line) and the associated probabilities that a particle will (a) diffuse into the non-tunnelling region from the bulk, (b) diffuse from the tunnelling to the non-tunnelling region, (c) move from non-tunnelling to tunnelling regions and (d) enter the adsorption region from the tunnelling region. Not to scale. Replicated from ref. 70 and 71 with permission from the Royal Society of Chemistry and Wiley VCH respectively.

'hydrodynamic adsorption', ${ }^{70}$ which can have noticeable experimental effects. ${ }^{74-76}$ Apart from computational intrigue, an electrocatalytic particle hydrodynamically adsorbed to the substrate will show qualitatively different current transients (Fig. 4) ${ }^{76}$ as well as modulate the contact between the particle and substrate. ${ }^{77,78}$

The state of agglomeration of nanoparticles has been investigated both computationally and experimentally, based on the assumption that agglomerates can be approximated as nanoparticles; $r_{\text {agg }} \approx$ $N r_{\text {mono }}$ where $N$ is the number of monomers in the agglomerate. Initial experiments suggest that destructive anodic particle coulometry (APC) quantitatively gave the state of agglomeration. ${ }^{79}$ Later work ${ }^{80}$ investigated the reversibility of the process, suggesting $\mathrm{Ag}$ NPs undergo reversible agglomeration in $\mathrm{KCl}$, however the decreased flux of larger particles limits the likelihood of observing agglomerate impacts. ${ }^{81}$

\section{Hydrodynamic systems}

Under conventional experimental conditions, the mass transport of nanoparticles is by Brownian motion, as described by Stokes-Einstein equation. The flux of the particles is largely assumed to be independent of the electrical field in the cell, because of the supporting electrolyte, such that the only external field acting on the particles is gravity. A few research groups have made some initial advancements into increasing the flux of particles to the substrate electrode by using convection, specifically microfluidic channels, ${ }^{82,83}$ magnetically stirred and microjet ${ }^{84}$ electrochemical cells. A key advantage of hydrodynamic (micro)electrodes is the flow rate and regime are readily controllable experimentally, so the mass transport to an electrode is easily managed. At first consideration, it could be assumed that as the flow rate increases, the particle impact frequency would increase, up to the limit of the equipment deployed. It was in fact found that the collision frequency increased with flow rate to a maximum, ${ }^{82,84}$ in both configurations (Fig. 5). Under magnetic stirring, Jian et al. ${ }^{84}$ recorded a near binary change in impact frequency; when the stirring was 

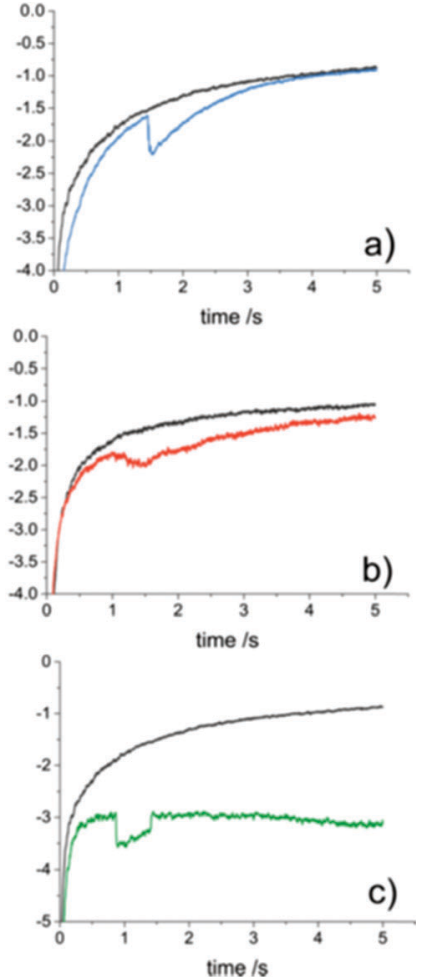

Fig. 4 Different current transient waveforms for proton reduction $(10 \mathrm{mM}$ $\left.\mathrm{HClO}_{4}, 0.6 \mathrm{M} \mathrm{NaClO}_{4}\right)$ at Au NPs on a carbon UME $\left(r_{0}=4.6 \mu \mathrm{m}\right)$ in the absence (black) and presence (coloured) of au NPs $\left(r_{\mathrm{NP}}=9.8 \pm 6.0 \mathrm{~nm}\right)$. (a) Step on-gradual off. (b) Gradual on-gradual off. (c) Step on-step off. Reproduced from ref. 76 with permission of the American Chemical Society.

off, there were negligible impacts recorded (Fig. 6), which was ascribed to the lower mass transfer.

\section{Exotic nanoparticle electrodes}

Mineral and hetero-nanostructures. Initially, nanoimpacts were largely carried out using metallic nanoparticles, but Tschulik et al. and Shimizu et al. reported the direct electrochemistry of both magnetite ${ }^{85}$ and haematite ${ }^{86}$ particles respectively, opening the field up to mineral nanomaterials. In a similar manner to the analysis of magnetite particles, ${ }^{85}$ layered transition metal dichalcogenides (LTDs, $\mathrm{MX}_{2}$ ) have been successfully investigated by nanoimpact methods by Lim et $a l^{87}$ That is to say, both mineral moieties can give cathodic and anodic current transients; magnetite can undergo direct oxidation (APC) and reduction (cathodic particle coulometry, CPC), while LTDs can be oxidised from $\mathrm{M}$ (Iv) to $\mathrm{M}$ (vI) or catalyse proton reduction.

Analysis of hetero-nanostructures, such as core@shell and decorated nanoparticles by impact methods is still in its infancy, compared to the field of nanoparticle electrochemistry. At the time of writing, there have only been 3 hetero-nanostructures probed, to the best of the authors' knowledge, covering supported particles ${ }^{77,78,83}$ and core@shell ${ }^{88}$ structures.

Investigation of $\mathrm{N}$-doped carbon nanotube supported palladium particles (Pd/N-CNT) demonstrated the motion of the nanotube at the interface. ${ }^{48,49}$ The physical movement at the substrate, due to the hydrodynamic adsorption, could interfere
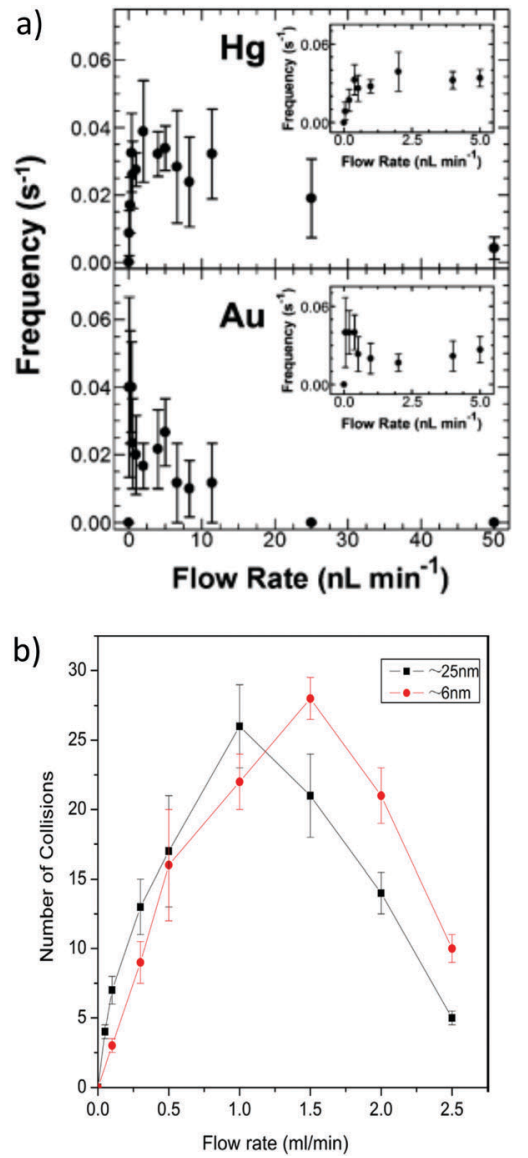

Fig. 5 Change of impact frequency with flow rate at (a) $\mathrm{Hg} / \mathrm{Pt}$ (top) and $\mathrm{Au}$ (bottom) microband UMEs and (b) face on microjet at an Hg/Pt UME. For full interpretation of figures, see the text details in the references. Reproduced from ref. 82 and 84 with permission of the American Chemical Society and Elsevier respectively.

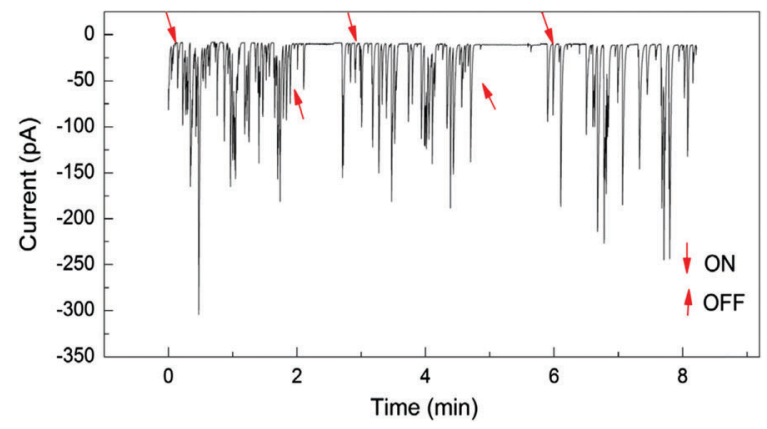

Fig. 6 Pt NP (25 nm) impacts at a $\mathrm{Hg} / \mathrm{Pt}$ UME at $-0.04 \mathrm{~V}$ (vs. SCE) under pulsed magnetic stirring, in phosphate buffered (50 mM, pH 7.5) $\mathrm{N}_{2} \mathrm{H}_{4}$ $(15 \mathrm{mM})$ solution. The arrows designated ON and OFF denote approximately where the stirring was switched on or off respectively. Reproduced from ref. 84 with permission of Elsevier.

with the electrical contact between the substrate and impinging particle, whereas the particle modified electrode showed a more stable current response. The other of the supported heteroparticles investigated were decorated magnetite, where the superparamagnetic magnetite particle supports were exposed to an 
external magnetic field. ${ }^{83,89}$ The magnetite support particles investigated were decorated with both platinum ${ }^{83}$ and Prussian Blue $^{89}$ and were studied in a microfluidic and conventional configurations, respectively. In both cases the flux and consequently frequency of impacts was increased by application of an external magnetic field. In the microfluidic experiment, it was noted that the convective forces also increased the collision frequency, ${ }^{82}$ but to a lesser extent than the applied magnetic field. To add to the extensive range of nanoparticles that can be sized using nanoimpact methods, Au@Ag core@shell particles have been analysed by Holt et al. ${ }^{88}$ by APC; the charge transferred by exhaustive oxidation was used to derive the size of the particles. In the same experiment, the chemistry of core, shell and alloy materials was investigated, by modelling a CV for the desired reaction, within reason, or analysing the transient decays. This type of analysis is yet to be investigated in depth, but could prove to be an invaluable advancement in the field, particularly with supported electrocatalysts for use in better understood systems like proton reduction, or methanol oxidation.

\section{Carbon nanoparticles and organic nanoparticles}

Carbon based NPs have not been overlooked in these investigations insofar as the first direct use of an organic amplifier species was the non-destructive tag-redox coulometry ${ }^{90}$ (TRC), where an inert particle is modified with an electrochemically active species. Graphene nanoflakes have been observed ${ }^{91}$ in a similar manner, ${ }^{92}$ where the flakes were grafted with a ferrocene derivative $\left(\mathrm{Fc}^{\prime}\right)$ as a redox tag. The unmodified graphene nanoflakes showed only capacitive current from particle charge/discharge. ${ }^{91}$ The $\mathrm{Fc}^{\prime}$ modified graphene showed both faradaic and capacitive currents, where the latter was approximately 10 fold lower. ${ }^{92}$ Other carbon nanomaterials acting as nanoparticle electrodes include fullerene clusters (nano- $\mathrm{C}_{60}$ ), reported by Stuart et al. ${ }^{93}$ and carbon nanotubes grafted onto an AuNP reported by Park et al. ${ }^{94}$ The nano- $\mathrm{C}_{60}$ experiments were conducted using direct electrochemistry of the fullerene clusters, while the carbon nanotubes made use of the area increase, when the particle contacted the electrode, with ferrocene as the indicator species.

The first fully organic nanoparticles analyse by this technique were re-precipitated indigo dye nanoparticles. ${ }^{95}$ The particle size determined was quantitative, as confirmed by dynamic light scattering (DLS). Indigo can undergo a 2 electron reduction to leuco-indigo (Fig. 7a) ${ }^{96}$ but aromatic hydrocarbons can also be stable to irreversible oxidation reactions and nanoimpact analysis has been shown to be robust toward the analysis of bifunctional magnetite nanoparticles. Following from that, oil blue dye particles, which can undergo 2 separate 1-electron oxidation and reduction reactions (Fig. 7b) was studied. ${ }^{97}$ The voltammetric response of oil blue dye, both in dry acetonitrile and deionised water (pH 6.8) was shown to be comparable to a substituted anthraquinone, and as such undergoes irreversible redox reactions wherein the charge transferred again allowed a quantitative size distribution to be derived, by both APC and CPC.

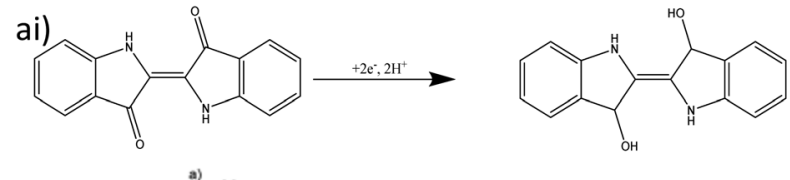

aii)
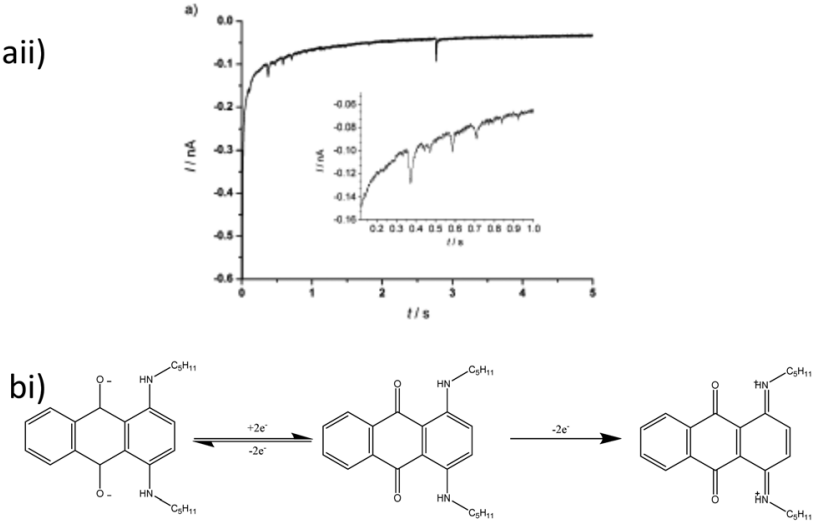

bii)
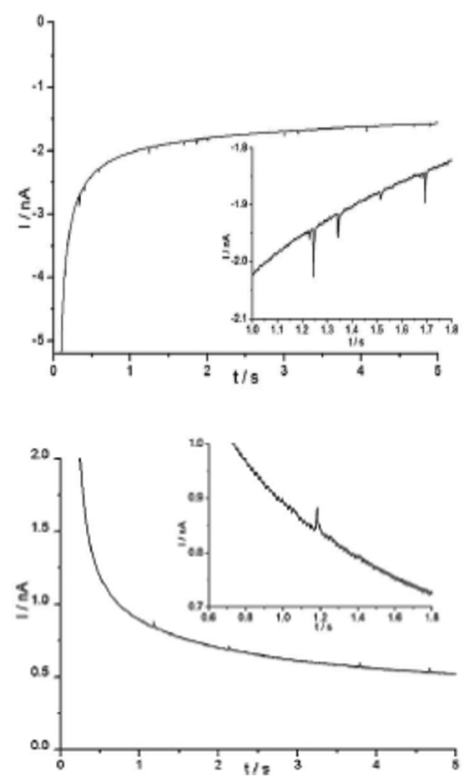

Fig. 7 (a) Indigo dye impact electrochemistry (i) reduction mechanism and (ii) impact current transient. (b) oil blue dye nanoimpacts (i) redox chemistry of oil blue dye and (ii) both cathodic (bottom left) and anodic (bottom right) impact transients for oil blue dye particles. All insets are magnified sections to show impact current spikes in more detail. Reproduced from ref. 95 and 97 with permission of Wiley $\mathrm{VCH}$ and the Royal Society of Chemistry respectively.

\section{Micelles and soft particles}

Above the critical micelle concentration (CMC), surfactants can encapsulate electroactive species. A relatively simple example is cetyltrimethyl ammonium bromide (CTAB), wherein the encapsulated $\mathrm{Br}^{-}$counterions are oxidised. ${ }^{98}$ It was shown that the current spikes only appear at $[\mathrm{CTAB}]>\mathrm{CMC}^{98,99}$ in electrolyte solution. The encapsulation of reactive species has been well studied recently, ${ }^{100-103}$ where the micelles formed act as nanoreactors containing as little as attolitres ${ }^{103}$ of analyte. Typical inorganic redox active species other than bromide have been uncommon in soft particle impacts, but Lebègue et al. ${ }^{100}$ 
measured the response of $\left[\mathrm{Fe}\left(\mathrm{CN}_{6}\right)\right]^{4-}$ encapsulated in a phospholipid vesicle. Electrochemically active biomolecules have been studied as vesicle reactors as well; the kinetic constant and turnover frequency of vitamin B12 mediated dehalogenation of trichloroethylene determined to be $29 \pm 4 \mathrm{mM}$ and $225 \pm 32 \mathrm{~s}^{-1}$ respectively. ${ }^{101}$ Interestingly, 'blank' vesicles impinging on an electrode give rise to a step on-step off type signal (vide supra), where the absolute limiting current decreases. ${ }^{100}$ The current steps observed by Lebègue $e t$ al. ${ }^{100}$ were qualitatively the same as those observed by impacts of insulating latex ${ }^{104}$ polystyrene ${ }^{105,106}$ and silica ${ }^{106}$ particles.

\section{Practical considerations for experimentalists}

It is challenging to develop a general set of rules for a successful nanoimpact experiment due to the multiple factors to account for. However, consideration of these factors, although complex, can aid in the design and troubleshooting of an experiment. Key factors affecting both direct and indirect type collision processes include:

\section{Particle number concentration}

In order to achieve a convenient, practical impact rate, whilst maintaining dispersion and minimising the probability of simultaneous impacts, a low number concentration is needed, with numerous studies using the $\mathrm{nM}$ to $\mathrm{pM}$ range. In concert with the ionic strength of the solution, high number concentrations can contribute to agglomeration and aggregation of the colloid. ${ }^{107,108}$

\section{Supporting electrolyte concentration}

Experiments require a sufficiently high supporting electrolyte concentration to suppress migration, however the ionic strength of the solution has a clear effect on the state of particle agglomeration or aggregation. ${ }^{79,80,107-110}$

\section{Signal : noise ratio}

Notwithstanding minimisation of electrical and instrumental noise levels, the magnitude of the current signals must be considered. In terms of direct experiments, the signal: noise ratio places a lower limit on the size of the particle, ${ }^{111}$ and for indirect experiments this limits the analyte concentration. ${ }^{110}$ For both direct and indirect experiments, increasing the number of electrons transferred during a reaction can improve the signal : noise ratio.

\section{Instrumentation}

The potentiostat employed must have low noise levels and ultralow $(<1 \mathrm{nA})$ detection. In addition, it must have fast rise times and sampling rates, compared to the timescale of the impact current transients. The sensitivity and rise times must be appropriate to the experiment, but can often be adjusted according to the objectives. Careful electrical grounding of equipment and the use of a Faraday cage is imperative.

\section{Conclusions and outlook}

Nanoelectrodes have been widely used to study fast electrode kinetics through a wide range of experimental techniques. Nanoparticle modified electrodes offer a facile starting point for analysis, but nanoimpact methods can give more detailed insight into electrochemistry at single particles. Nanoimpact methods have been extensively used to analyse a wide range of nanomaterials, but the field has scope to develop further. Fast reaction kinetics and synthetic methods have received less attention than computational methods and physical analysis under nanoimpact regimes and offer further means of probing surface chemistry at nanocolloids.

\section{List of abbreviations}

$\begin{array}{ll}\text { AA } & \text { Ascorbic acid } \\ \text { APC } & \text { Anodic particle coulometry } \\ \text { BV } & \text { Butler-Volmer } \\ C_{0} & \text { Bulk concentration } \\ \text { CMC } & \text { Critical micelle concentration } \\ \text { CPC } & \text { Cathodic particle coulometry } \\ \text { CTAB } & \text { Cetyltrimethylammonium bromide } \\ \text { CV } & \text { Cyclic voltammetry } \\ \text { DA } & \text { Dopamine } \\ \text { DLS } & \text { Dynamic light scattering } \\ D_{x} & \text { Diffusion coefficient of species } x \\ \text { EDL } & \text { Electrical double layer } \\ E_{\mathrm{f}}^{0} & \text { Formal potential } \\ \text { ET } & \text { Electron transfer } \\ \text { Fc } & \text { Ferrocene derivative } \\ I_{\text {lim }} & \text { Limiting current } \\ \text { LOD } & \text { Limit of detection } \\ \text { LTD } & \text { Layered transition metal dichalcogenide } \\ \text { MH } & \text { Marcus-Hush } \\ \text { MHC } & \text { Marcus-Hush-Chidsey } \\ \text { NEA } & \text { Nanoelectrode array } \\ \text { NP } & \text { Nanoparticle } \\ r_{0} & \text { Nominal electrode radius } \\ r_{\text {agg }} & \text { Radius of aggregate particle } \\ r_{\text {mono }} & \text { Radius of monomer component of aggregate(s) } \\ r_{\mathrm{NP}} & \text { Nanoparticle radius } \\ \text { TRC } & \text { Orfective diffusion layer thickness } \\ \text { UA } & \\ \delta_{\text {eff }} & \eta \\ \lambda & \text { Overpotential } \\ & \end{array}$

\section{Acknowledgements}

The Authors acknowledge financial support from the EPSRC, through the Centre for Doctoral Training in Fuel Cells and their Fuels. 


\section{Notes and References}

1 E. Roduner, Chem. Soc. Rev., 2006, 35, 583-592.

2 G. Schmid, Chem. Rev., 1992, 92, 1709-1727.

3 C. Rao, G. Kulkarni, P. Thomas and P. Edwards, Chem. Eur. J., 2002, 8, 28-35.

4 B. K. Teo, J. Cluster Sci., 2013, 25, 5-28.

5 M.-C. Daniel and D. Astruc, Chem. Rev., 2004, 104, 293-346.

6 B. Gates, Chem. Rev., 1995, 95, 511-522.

7 Z. Xu, F. Xiao, S. Purnell, O. Alexeev, S. Kwai, S. Deutsch and B. Gates, Nature, 1994, 372, 346-348.

8 J. Greeley, J. K. Nørskov and M. Mavrikakis, Annu. Rev. Phys. Chem., 2002, 53, 319-348.

9 B. F. G. Johnson, Coord. Chem. Rev., 1999, 190-192, 1269-1285.

10 A. Choplin and F. Quignard, Coord. Chem. Rev., 1998, 178-180, 1679-1702.

11 S. Chen and Y. Liu, Phys. Chem. Chem. Phys., 2014, 16, 635-652.

12 D. W. M. Arrigan, Analyst, 2004, 129, 1157-1165.

13 I. Streeter, R. Baron and R. G. Compton, J. Phys. Chem. C, 2007, 111, 17008-17014.

14 M. V. Mirkin, W. Nogala, J. Velmurugan and Y. Wang, Phys. Chem. Chem. Phys., 2011, 13, 21196-21212.

15 H. G. Park and J. K. Holt, Energy Environ. Sci., 2010, 3, 1028-1036.

16 X. Xie, D. Stueben and Z. Berner, Anal. Lett., 2005, 38, 2281-2300.

17 C. M. Li and W. Hu, J. Electroanal. Chem., 2013, 688, 20-31.

18 N. V. Rees, Electrochem. Commun., 2014, 43, 83-86.

19 S. M. Oja, M. Wood and B. Zhang, Anal. Chem., 2013, 85, 473-486.

20 S. M. Oja, Y. Fan, C. M. Armstrong, P. Defnet and B. Zhang, Anal. Chem., 2016, 88, 414-430.

21 A. J. Bard and L. R. Faulkner, Electrochemical Methods: Fundamentals and Applications, John Wiley \& Sons, Inc., New York, 2nd edn, 2001, pp. 137-155.

22 A. J. Bard and L. R. Faulkner, Electrochemical Methods: Fundamentals and Applications, John Wiley \& Sons, Inc., New York, 2nd edn, 2001, pp. 534-579.

23 R. He, S. Chen, F. Yang and B. Wu, J. Phys. Chem. B, 2006, 110, 3262-3270.

24 E. J. F. Dickinson and R. G. Compton, J. Phys. Chem. C, 2009, 113, 17585-17589.

25 X. Yang and G. Zhang, Nanotechnology, 2007, 18, 335201.

26 S. Yu, L. Yuwen, L. Zhixiu, X. Lu, W. Aili and C. Shengli, J. Phys. Chem. C, 2009, 113, 9878-9883.

27 S. W. Feldberg, Anal. Chem., 2010, 82, 5176-5183.

28 J. T. Cox and B. Zhang, Annu. Rev. Anal. Chem., 2012, 5, 253-272.

29 X. J. Huang, A. M. O'Mahony and R. G. Compton, Small, 2009, 5, 776-788.

30 Y. Chen and A. Pepin, Electrophoresis, 2001, 22, 187-207.

31 Y. Chen, Microelectron. Eng., 2015, 135, 57-72.

32 S. R. Belding, F. W. Campbell, E. J. F. Dickinson and R. G. Compton, Phys. Chem. Chem. Phys., 2010, 12, 11208-11221.

33 F. W. Campbell, S. R. Belding, R. Baron, L. Xiao and R. G. Compton, J. Phys. Chem. C, 2009, 113, 14852-14857.
34 N. Godino, X. Borrise, F. X. Munoz, F. J. del Campo and R. G. Compton, J. Phys. Chem. C, 2009, 113, 11119-11125.

35 T. J. Davies, S. Ward-Jones, C. E. Banks, J. del Campo, R. Mas, F. X. Muñoz and R. G. Compton, J. Electroanal. Chem., 2005, 585, 51-62.

36 G. Aragay and A. Merkoci, Electrochim. Acta, 2012, 84, 49-61.

37 M. Li, H. Gou, I. Al-Ogaidi and N. Wu, ACS Sustainable Chem. Eng., 2013, 1, 713-723.

38 M. B. Gumpu, S. Sethuraman, U. M. Krishnan and J. B. B. Rayappan, Sens. Actuators, B, 2015, 213, 515-533.

39 G. March, T. Nguyen and B. Piro, Biosensors, 2015, 5, 241-275.

40 S. Thatai, P. Khurana, J. Boken, S. Prasad and D. Kumar, Microchem. J., 2014, 116, 62-76.

41 L. Rassaei, F. Marken, M. Sillanpää, M. Amiri, C. M. Cirtiu and M. Sillanpää, TrAC, Trends Anal. Chem., 2011, 30, 1704-1715.

42 B. J. Sanghavi, O. S. Wolfbeis, T. Hirsch and N. S. Swami, Microchim. Acta, 2015, 182, 1-41.

43 M. Holzinger, A. Le Goff and S. Cosnier, Front. Chem., 2014, 2, 63-73.

44 A. Chen and S. Chatterjee, Chem. Soc. Rev., 2013, 42, 5425-5438.

45 W. Siangproh, W. Dungchai, P. Rattanarat and O. Chailapakul, Anal. Chim. Acta, 2011, 690, 10-25.

46 B. Uslu and S. a. Ozkan, Anal. Lett., 2011, 44, 2644-2702.

47 B. K. Jena and C. R. Raj, Anal. Chem., 2008, 80, 4836-4844.

48 X. Dai, O. Nekrassova, M. E. Hyde and R. G. Compton, Anal. Chem., 2004, 76, 5924-5929.

49 W. Yantasee, K. Hongsirikarn, C. L. Warner, D. Choi, T. Sangvanich, M. B. Toloczko, M. G. Warner, G. E. Fryxell, R. S. Addleman and C. Timchalk, Analyst, 2008, 133, 348-355.

50 M.-P. N. Bui, C. A. Li, K. N. Han, X.-H. Pham and G. H. Seong, Anal. Sci., 2012, 28, 699-704.

51 S. Mahshid, C. Li, S. S. Mahshid, M. Askari, A. Dolati, L. Yang, S. Luo and Q. Cai, Analyst, 2011, 136, 2322-2329.

52 T.-Q. Xu, Q.-L. Zhang, J.-N. Zheng, Z.-Y. Lv, J. Wei, A.J. Wang and J.-J. Feng, Electrochim. Acta, 2014, 115, 109-115.

53 M. Heyrovsky and J. Jirkovsky, Langmuir, 1995, 11, 4288-4292.

54 M. Heyrovsky, J. Jirkovsky and M. Struplova-Bartackova, Langmuir, 1995, 11, 4309-4312.

55 M. Heyrovsky, J. Jirovsky and B. R. Muller, Langmuir, 1995, 11, 4293-4299.

56 M. Heyrovsky, J. Jirovsky and M. Struplova-Bartackova, Langmuir, 1995, 11, 4300-4308.

57 X. Xiao and A. J. Bard, J. Am. Chem. Soc., 2007, 129, 9610-9612.

58 N. V. Rees, Y.-G. Zhou and R. G. Compton, RSC Adv., 2012, 2, 379-384.

59 P. A. Bobbert, M. M. Wind and J. Vlieger, Physica A, 1987, 141, 58-72.

60 C. Batchelor-McAuley, E. J. F. Dickinson, N. V Rees, K. E. Toghill and R. G. Compton, Anal. Chem., 2012, 84, 669-684. 
61 E. Kätelhön, E. E. L. Tanner, C. Batchelor-McAuley and R. G. Compton, Electrochim. Acta, 2016, 199, 297-304.

62 W. Cheng and R. G. Compton, Trends Anal. Chem., 2014, 58, 79-89.

63 S. Eloul and R. G. Compton, J. Phys. Chem. C, 2015, 119, 27540-27549.

64 E. J. E. Stuart, N. V. Rees and R. G. Compton, Chem. Phys. Lett., 2012, 531, 94-97.

65 E. O. Barnes, Y.-G. Zhou, N. V. Rees and R. G. Compton, J. Electroanal. Chem., 2013, 691, 28-34.

66 E. J. E. Stuart, Y.-G. Zhou, N. V. Rees and R. G. Compton, RSC Adv., 2012, 2, 6879-6884.

67 J. M. Kahk, N. V. Rees, J. Pillay, R. Tshikhudo, S. Vilakazi and R. G. Compton, Nano Today, 2012, 7, 174-179.

68 B. Haddou, N. V Rees and R. G. Compton, Phys. Chem. Chem. Phys., 2012, 14, 13612-13617.

69 Y.-G. Zhou, N. V. Rees and R. G. Compton, Angew. Chem., Int. Ed., 2011, 50, 4219-4221.

70 E. Kätelhön and R. G. Compton, Chem. Sci., 2014, 5, 4592-4598.

71 E. Kätelhön and R. G. Compton, ChemElectroChem, 2015, 2, 64-67.

72 Y. Kazoe and M. Yoda, Appl. Phys. Lett., 2011, 99, 124104.

73 M. a. Bevan and D. C. Prieve, J. Chem. Phys., 2000, 113, 1228-1236.

74 E. Kätelhön, S. V. Sokolov and R. G. Compton, Sens. Actuators, B, 2016, 234, 420-425.

75 S. Eloul, E. Kätelhön, C. Batchelor-McAuley, K. Tschulik and R. G. Compton, J. Electroanal. Chem., 2015, 755, 136-142.

76 L. S. Y. Ly, C. Batchelor-McAuley, K. Tschulik, E. Kätelhön and R. G. Compton, J. Phys. Chem. C, 2014, 118, 17756-17763.

77 X. Li, C. Batchelor-Mcauley, S. A. I. Whitby, K. Tschulik, L. Shao and R. G. Compton, Angew. Chem., Int. Ed., 2016, 55, 4296-4299.

78 H. Hodson, X. Li, C. Batchelor-McAuley, L. Shao and R. G. Compton, J. Phys. Chem. C, 2016, 120, 6281-6286.

79 J. Ellison, K. Tschulik, E. J. E. Stuart, K. Jurkschat, D. Omanović, M. Uhlemann, A. Crossley and R. G. Compton, ChemistryOpen, 2013, 2, 69-75.

80 S. V. Sokolov, K. Tschulik, C. Batchelor-McAuley, K. Jurkschat and R. G. Compton, Anal. Chem., 2015, 87, 10033-10039.

81 S. V. Sokolov, E. Kätelhön and R. G. Compton, J. Electroanal. Chem., 2016, DOI: 10.1016/j.jelechem.2016.01.023.

82 T. M. Alligrant, M. J. Anderson, R. Dasari, K. J. Stevenson and R. M. Crooks, Langmuir, 2014, 30, 13462-13469.

83 D. A. Robinson, J. J. Yoo, A. D. Casraneda, B. Gu, R. Dasari, R. M. Crooks and K. J. Stevenson, ACS Nano, 2015, 9, 7583-7595.

84 J. Jiang, X. Huang and L. Wang, J. Colloid Interface Sci., 2016, 467, 158-164.

85 K. Tschulik, B. Haddou, D. Omanović, N. V. Rees and R. G. Compton, Nano Res., 2013, 6, 836-841.
86 K. Shimizu, K. Tschulik and R. G. Compton, Chem. Sci., 2016, 7, 1-7.

87 C. S. Lim, S. M. Tan, Z. Sofer and M. Pumera, ACS Nano, 2015, 9, 8474-8483.

88 L. R. Holt, B. J. Plowman, N. P. Young, K. Tschulik and R. G. Compton, Angew. Chem., Int. Ed., 2016, 55, 397-400.

89 G. P. Santos, A. F. Melo and F. N. Crespilho, Phys. Chem. Chem. Phys., 2014, 16, 8012-8018.

90 N. V. Rees, Y.-G. Zhou and R. G. Compton, Chem. Phys. Lett., 2012, 525-526, 69-71.

91 J. Poon, C. Batchelor-McAuley, K. Tschulik and R. G. Compton, Chem. Sci., 2015, 6, 2869-2876.

$92 \mathrm{H}$. Wu, Q. Lin, C. Batchelor-McAUley, L. M. Gonçalves, C. F. R. A. C. Lima and R. G. Compton, Analyst, 2016, 141, 2696-2703.

93 E. J. E. Stuart, K. Tschulik, C. Batchelor-McAuley and R. G. Compton, ACS Nano, 2014, 8, 7648-7654.

94 J. H. Park, S. N. Thorgaard, B. Zhang and A. J. Bard, J. Am. Chem. Soc., 2013, 135, 5258-5261.

95 W. Cheng, X. F. Zhou and R. G. Compton, Angew. Chem., Int. Ed., 2013, 52, 12980-12982.

96 A. M. Bond, F. Marken, E. Hill, R. G. Compton and H. Hügel, J. Chem. Soc., Perkin Trans. 2, 1997, 1735-1742.

97 X.-F. Zhou, W. Cheng and R. G. Compton, Nanoscale, 2014, 6, 6873-6878.

98 H. S. Toh and R. G. Compton, Chem. Sci., 2015, 6, 5053-5058.

99 K. Kuperkar, L. Abezgauz, K. Prasad and P. Bahadur, J. Surfactants Deterg., 2010, 13, 293-303.

100 E. Lebègue, C. M. Anderson, J. E. Dick, L. J. Webb and A. J. Bard, Langmuir, 2015, 31, 11734-11739.

101 W. Cheng and R. G. Compton, Angew. Chem., Int. Ed., 2016, 55, 2545-2549.

102 W. Cheng and R. G. Compton, Angew. Chem., Int. Ed., 2015, 54, 7082-7085.

103 B. K. Kim, J. Kim and A. J. Bard, J. Am. Chem. Soc., 2015, 137, 2343-2349.

104 B. M. Quinn, P. G. Van't Hof and S. G. Lemay, J. Am. Chem. Soc., 2004, 126, 8360-8361.

105 A. Boika and A. J. Bard, Anal. Chem., 2015, 87, 4341-4346.

106 A. Boika, S. N. Thorgaard and A. J. Bard, J. Phys. Chem. B, 2013, 117, 4371-4380.

107 J. Eastman, in Colloid Science: Principles, Methods and Applications, ed. T. Cosgrove, Wiley-Blackwell, Hoboken N. J., 2nd edn, 2010, pp. 45-59.

108 A. R. Petosa, D. P. Jaisi, I. R. Quevedo, M. Elimelech and N. Tufenkji, Environ. Sci. Technol., 2010, 44, 6532-6549.

109 J. C. Lees, J. Ellison, C. Batchelor-Mcauley, K. Tschulik, C. Damm, D. Omanović and R. G. Compton, ChemPhysChem, 2013, 14, 3895-3897.

110 S. E. F. Kleijn, B. Serrano-Bou, A. I. Yanson and M. T. M. Koper, Langmuir, 2013, 29, 2054-2064.

111 T. R. Bartlett, S. V. Sokolov and R. G. Compton, ChemistryOpen, 2015, 4, 600-605. 